\title{
A AVALIAÇÃO DA ESCOLA PÚBLICA DE MINAS GERAIS 1
}

MARIA ALBA DE SOUZA*

\section{1 - Introdução}

O Estado de Minas Gerais vem, desde 1991, enfrentando o desafio de melhorar a qualidade do ensino oferecido pelas escolas públicas estaduais. A partir da identificação dos agentes da educação - o aluno, os pais ou os responsáveis pelo aluno, o profissional da educaçăo (professor, especialista, funcionário, serviçal) e a escola - foram estabelecidos compromissos com esses agentes, nos quais se evidenciaram cinco grandes prioridades que, asseguradas, deveriam nortear todo o processo educacional no Estado:

1 - autonomia da escola;

2 - fortalecimento da direçäo da escola;

3 - aperfeiçoamento e capacitaçăo de especialistas, professores e funcionários;

4 - avaliação do Sistema Estadual de Educação;

5 - integraçăo com os Municípios do Estado.

Dentro dessas diretrizes políticas, a avaliação do sistema educacional do Estado foi enfocada como elemento básico e instrumento fundamental para o conhecimento da realidade educacional, para a identificação dos pontos críticos e, conseqüentemente, para a melhoria, a implementação e o acompanhamento das ações necessárias para se atingir a qualidade da educação.

Com o respaldo da Constituição do Estado (1989), a decisão política de avaliar a qualidade do ensino e a sensibilizaçäo de todos os segmentos da

- Diretora de Dirctoria de Avalinglo do Ensino, Superiatendenctia de Desenvolvimento do Bnsino - Secretaria de Estado da Educaçǘ de Minns Gerais.

1 Paper apresentado no seninário Indicadores da Qualldade e Produtividnde no Serviço Público. IPEA - Instituto de Pesquisa Ecanberiea Aplicada. CENDEC - Centro de Treimamento para o Desanvolvimento Econtemico e Social. Brnstlia, DF. 06707 denemibro de 1995. 
sociedade ficou determinado o marco do Programa de Avaliação da Escola Pública de Minas Gerais,

Para o planejamento desse Programa, pelo menos cinco aspectos teriam, de imediato, que ser considerados: QUEM? PARA QUÊ? O QUÊ? COMO? QUANDO? e a resposta para cada um deles tinha implicaçôes que iriam interferir na especificação do processo e na tomada de decisão objetivando a definição de instrumentos adequados aos propósitos do Estado e ao contexto educacional brasileiro.

\section{2 - Aspectos considerados para a efetivação do Programa de Avaliação da Escola Púhlica de Minas Gerais}

\subsection{Quem deve ser avaliado?}

Sob esse aspecto seria conveniente considerar que há uma tendência internacional de sub-utilização das informaçôes obtidas em avaliações para subsidiar a formulação de políticas públicas (Abramowicz, 1994), tendência essa que, naturalmente, se reflete no Brasil. Além disso, ao se desencadear o processo de avaliação em Minas Gerais, a equipe avaliadora teria que se defrontar com a resistência normal que sempre permeou a prática da avaliação.

Diante disso, procurou-se definir o Programa de Avaliação, levando-se em conta o seu papel extrapolador de uma mera verificação do rendimento do aluno para se tornar um instrumento de relevante contribuição na garantia de maior eficiência de todo o sistema.

Portanto, era necessário ficar bem claro para a comunidade escolar que a avaliação abrangeria todos os segmentos do sistema de ensino e que não seria uma avaliação de desempenho do docente ou, simplesmente, do discente, mas um importante auxiliar da prática educacional.

Para Bloom, a avaliação é um sistema de controle de qualidade pelo qual se pode determinar, a cada passo do processo ensino-aprendizagem, se este está sendo eficaz ou não; e caso não o esteja, que mudanças devem ser feitas a fim de assegurar sua eficácia antes que seja tarde demais (Bloom et alii, 1983). $E$ a avaliação de Minas, assim entendida, passou a contar com parceiros dedicados e de suma importância no sucesso de tal empreendimento.

\subsection{Para que avaliar?}

Os objetivos do Programa de avaliação abrangeram quatro aspectos que caracterizaram os propósitos de uma avaliação institucional tendo em vista a qualidade do ensino nas escolas estaduais:

I. conhecer o desempenho dos alunos em aspectos cognitivos dos conteúdos curriculares; 
II. levantar dados e informaçōes para servirem de subsidios na tomada de decisőes sobre o desenvolvimento do processo de ensino;

III. identificar, nos conteúdos curriculares, pontos críticos que necessitam maior atenção e requerem intervenção imediata e prioritária para a melhoria da aprendizagem;

IV. fornecer, a partir dos dados levantados, subsídios para que os professores possam atuar com maior eficiência na condução do processo de ensino e a Secretaria da Educação possa colaborar para maior eficiência do Sistema.

Em síntese, este Programa de Avaliação da Escola Pública do Estado pretende realizar dignóstico e compor acervo de dados e informaçŏes consistentes sobre as escolas, com vistas a obter uma base importante para implementação de um plano de melhoria do ensino que venha a intervir na baixa produtividade do Sistema e nos elevados índices de retençăo dos alunos, sobretudo nas séries iniciais do Ensino Fundamental.

\subsection{O que avaliar?}

A resposta para esta questão nos conduz ao pressuposto de que a avaliação da qualidade na educaçăo exige a consideraçäo de alguns aspectos relevantes. Limitar-se à verificaçăo do rendimento escolar seria restringir-se a um aspecto de todo o processo educacional. Assim sendo, o programa deveria avaliar, também, algumas variáveis relacionadas ao contexto escolar e a fatores não ligados diretamente à escola (dados familiares, recursos educacionais, etc.) mas que interferem no processo de ensino-aprendizagem.

Dessa forma, foram considerados como elementos de "entrada" informações ligadas à escola, tais como as características do corpo docente, programas escolares, etc; como elementos do "processo"-propostas curriculares e práticas instrucionais e como "produto" propriamente dito, aqui entendido como o aluno, a formaçăo de atitudes e o desempenho escolar.

\subsection{Como avaliar?}

Várias decisőes teriam que ser tomadas neste sentido para o planejamento do Programa de Avaliaçäo do Sistema de Ensino e, principalmente, para a sua adequaçăo ao contexto educacional brasileiro e à realidade do Estado.

Decidiu-se, entäo, levar em consideraçäo o propósito de criar uma cultura de avaliação em todo o Estado.

Assim ficou definido que:

a) a implementação do Programa teria o gerenciamento da Secretaria de Estado da Educação, por meio da Diretoria de Avaliação de Ensino criada especificamente para este fim. Paralelamente estão envolvidos órgåos regio- 
nais e elementos das próprias unidades de ensino, Diretores, Especialistas, Professores e Colegiado da escola. Assim, em todas as fases, desde a organização e aplicação dos instrumentos, à análise, disseminaçäo e uso dos resultados, o processo envolve os três níveis de administração: central, regional e local.

b) três instrumentos básicos deveriam ser utilizados para a pesquisa do rendimento escolar:

- provas

- questionário do aluno

- questionário da escola

As provas săo elaboradas de forma a permitir a identificaçäo, a partir de um conjunto de conhecimento, daquelas áreas críticas (non - mastery) que merecem reforço para aprendizagem. Juntamente com a mensuraçäo do desempenho, são também avaliados os comportamentos - conhecimento, compreensão e uso do conhecimento. Nesta fase, conta-se com a participação de professores com experiência em sala de aula e atuantes no ensino das diversas disciplinas.

Do Questionário do Aluno constam itens que levam a obter informações consideradas de relevante importancia para conhecimento da realidade do aluno, tais como: seus dados pessoais, seus hábitos escolares, suas pretensões educacionais e algumas variáveis ś́cio-econômicas e educacionais de sua família.

O Questionário da Escola contém questōes cujas respostas possibilitam reunir informaçōes gerais sobre o seu funcionamento, o seu corpo docente, os seus procedimentos relativos à organizaçio administrativa e à conduçđo pedagógica para melhor promover a aprendizagem. Constam, ainda, do Questionário itens que se destinam a dar conhecimento da forma como săo ministrados os conteúdos de cada disciplina avaliada, sob o ponto de vista do professor. Para que os dados obtidos mediante as respostas a esse Questionário reflitam a realidade da escola, essas informaçōes são fornecidas pela direçăo, pelos representantes do Colegiado, pelos especialistas e docentes da escola.

c) Manuais de Orientaçăo: esses manuais, elaborados pela equipe organizadora, șio específicos para cada função a ser exercida e destinados a nortear o desempenho das atividades dos grupos de trabalho, formados nos três níveis da administração. Dentre essas funçỗes, considera-se de relevante importância aquela que envolve os pais ou responsáveis pelos alunos, membros integrantes do Colegiado da Escola e por ele indicados - o Controlador de Qualidade.

O trabalho de análise dos resultados da avaliaçåo e de elaboração de Relatórios Finais, desenvolvido pela Escola (Diretores, Especialistas e Docentes), é também norteado por Manual que tem por objetivo garantir a homogeneidade da avaliaçăo em todo o Estado, facilitar a consolidaçăo geral pelo Örgäo Central, contribuir para melhor compreensão dos dados estatísticos descritivos, bem como levar a uma reflexão a respeito dos pontos críticos diagnosticados e a uma atuaçăo interveniente. Esses Relatórios constituem a 
fotografia de cada escola como diagnóstico fundamental para a elaboração do seu "Plano de Desenvolvimento da Escola" (PDE) e conseqüientemente o seu Plano Pedagógico de Ação.

Com o envolvimento de vários segmentos da área educacional e com a utilização de Manuais normativos para todas as funçōes resta ao Órgão Central providenciar treinamentos que possam clarear todo processo do Programa de Avaliaçäo. Esses treinamentos ocorrem como preparatórios operacionais antes de qualquer experiência de avaliação prevista no Programa, e como preparatórios para análise de dados após a emissão dos resultados de cada avaliaçฐ๊̃o. Participam desses treinamentos elementos dos órgåos regionais que têm a incumbência de multiplicá-los para os órgăos locais. Os treinamentos constituem uma fase de peso dentro de todo o trabalho, considerando o quantitativo de recursos humanos envolvidos e o pioneirismo da açăo. Dessa forma, procura-se assegurar maior homogeneidade nas ações, e evitar inovações e ocorrencias de fatos que possam vir a comprometer o êxito de todo o Programa.

\subsection{Quando avaliar?}

Com a opçäo de uma avaliação censitária, o Programa de Avaliaçäo da Escola Pública do Estado inclui avaliações sistemáticas de cinco séries escolares selecionadas, que representam término de ciclo ou de grau de ensino, tais como:

- início da $3^{\mathrm{a}}$ série - por permitir verificar em que medida o Ciclo Básico de Alfabetização (CBA) estaria conseguindo atingir com êxito seus objetivos;

$-5^{a}$ série do Ensino Fundamental - por representar mudança na vida do aluno que deixa a primeira fase do Ensino Fundamental, ingressando numa segunda fase onde o ensino é diversificado em seu conteúdo, nas metodologias adotadas e na pluralidade dos professores;

- $8^{2}$ série do Ensino Fundamental - por constituir término do Ensino Fundamental;

$-2^{a}$ série do Ensino Médio - por constituir a série do Ensino Médio que ainda năo se acha totalmente contaminada pelos cursos preparatórios para o acesso às universidades;

- série concluinte do Curso de Magistério (Professor de $1^{\mathrm{a}}$ a $4^{\mathrm{a}}$ série do $1^{\circ}$ grau) - por possibilitar conhecer aspectos de formação dos futuros professores que irão atuar nas quatro primeiras séries do Ensino Fundamental.

Os resultados das avaliações, dessas séries, fornecem subsídios sobre o sistema, em algumas áreas de conteúdos consideradas importantes nas séries avaliadas e nas séries antecedentes que năo foram privilegiadas com o processo formal da avaliação sistemica. Dessa forma, estão sendo envolvidos os profissionais da educação na responsabilidade de um melhor desempenho da escola, gerando um maior comprometimento de todos. 
Conforme a metodologia do Programa, o rendimento dos alunos das séries selecionadas é avaliado a cada dois anos, denominados Ciclos, possibilitando a todo sistema um período para implementaçăo de medidas de intervençăo e correçăo das deficiências detectadas, antes da avaliação subseqüente.

A aplicação da avaliaçắo numa mesma série no $2^{\circ}$ Ciclo possibilita, também, ao sistema comparar os resultados desta experiência com a do $1^{\circ}$ Ciclo.

Dessa forma, de março de 1992 a dezembro de 1993, Minas concretizou o $1^{\circ}$ Ciclo do Programa e de março de 1994 a novembro de 1995 , o $2^{\circ}$ Ciclo, conforme o quadro que segue:

\begin{tabular}{|c|c|c|c|c|c|c|c|c|c|}
\hline & \multirow{3}{*}{ Ano } & \multirow{3}{*}{ Mes } & \multirow{3}{*}{ Avalluçăo } & \multirow{3}{*}{$\begin{array}{c}\mathrm{N}^{\circ} \text { de } \\
\text { Alumos }\end{array}$} & \multirow{3}{*}{$\begin{array}{l}N^{N} \text { de } \\
\text { Escolas }\end{array}$} & \multicolumn{4}{|c|}{ Recursas firmanos } \\
\hline & & & & & & \multirow{2}{*}{$\begin{array}{c}\text { SRE } \\
\text { TÉenloos }\end{array}$} & \multicolumn{3}{|c|}{ UE } \\
\hline & & & & & & & Delectir & Putcosures & $\begin{array}{l}\text { Pals de } \\
\text { Alimoss }\end{array}$ \\
\hline بे & $\begin{array}{l}1992 \\
1992 \\
1993 \\
1993 \\
1993\end{array}$ & $\begin{array}{c}\text { plarpo } \\
\text { november } \\
\text { november } \\
\text { november } \\
\text { november }\end{array}$ & $\begin{array}{l}\text { AVACBA } \\
\text { OITAVA } \\
\text { QUINTAVA } \\
\text { AVASSEM } \\
\text { AVAMAG }\end{array}$ & $\begin{array}{r}325,000 \\
124.000 \\
407.443 \\
69.163 \\
6.760\end{array}$ & $\begin{array}{r}5.770 \\
2,173 \\
5.353 \\
813 \\
434\end{array}$ & $\begin{array}{r}1.795 \\
1.441 \\
1.407 \\
987 \\
874\end{array}$ & $\begin{array}{r}1.574 \\
7.131 \\
9.052 \\
3.209 \\
1.771\end{array}$ & $\begin{array}{r}19.698 \\
6.958 \\
19.556 \\
5.539 \\
1.300\end{array}$ & $\begin{array}{r}7.059 \\
3.555 \\
4.982 \\
1.367 \\
668\end{array}$ \\
\hline $\begin{array}{c}2^{\circ} \\
0 \\
0 \\
0 \\
\end{array}$ & $\begin{array}{l}1994 \\
1994 \\
1995 \\
1995 \\
1995\end{array}$ & $\begin{array}{c}\text { março } \\
\text { nuvember } \\
\text { november } \\
\text { navember } \\
\text { november }\end{array}$ & $\begin{array}{l}\text { AVACBA } \\
\text { QUINTAVA } \\
\text { OTTAVA } \\
\text { AVASSEM } \\
\text { AVAMAG }\end{array}$ & $\begin{array}{r}356.530 \\
265.645 \\
162.000 \\
102.050 \\
17.782\end{array}$ & $\begin{array}{r}4.764 \\
5.570 \\
2.604 \\
1.044 \\
548\end{array}$ & $\begin{array}{r}1.723 \\
1.145 \\
1.500 \\
1.000 \\
900\end{array}$ & $\begin{array}{r}13.328 \\
8.541 \\
7.500 \\
3.300 \\
1.800\end{array}$ & $\begin{array}{r}20.627 \\
20.381 \\
7.000 \\
5.600 \\
1.500\end{array}$ & $\begin{array}{r}6.746 \\
5.632 \\
4.000 \\
1.5001 \\
700\end{array}$ \\
\hline \multicolumn{3}{|c|}{ TOTAL. } & 10 & 1.836 .353 & . & 12773 & 67.206 & 108.159 & 36.209 \\
\hline
\end{tabular}

Fonte: DISID/DAVE/SEE

\section{Identificação das siglas:}

- SRE - Superintendência Regional de Ensino

- UE - Unidade Escolar

- AVACBA-Avaliação do Rendimento doAluno do Ciclo Básico deAlfabetizaçăo

- QUINTAVA - Avaliação do Rendimento do Aluno da $5^{a}$ série do Ensino Fundamental

- OITAVA - Avaliaçäo do Rendimento do Aluno da $8^{\mathrm{a}}$ série do Ensino Fundamental

- AVASSEM - Avaliação do Rendimento do Aluno da 2 série do Ensino Médio

- AVAMAG - Avaliação do Rendimento do Aluno da série concluinte do Curso deMagistério (Prof. de $1^{2}$ a $4^{a}$ série do $1^{\circ}$ grau)

\section{3 - Disseminação dos Resultados}

O plano de difusão e disseminação dos resultados deve ser desenhado desde o início do processo e deve contemplar um processo de sensibilizaçăo, 
de informação, de distribuição oportuna de resultados, de interpretaçăo e uso dos mesmos (Himmel, 1993). Decidir "o quê", "a quem" e "como" informar é decisåo que deve delimitar o desenvolvimento e o processo de todo o programa. Considerando que os resultados da avaliação devem fornecer informação útil e significativa, devem ser de interesse público e proporcionar soluções de melhoria, ampla difusäo é realizada no Estado, para que toda a comunidade conheça os resultados do programa de Avaliaçäo. Os informes oferecidos proporcionam uma descriçấo dos aspectos mais relevantes e oferecem indicadores da qualidade do trabalho, assim como identificam os pontos criticos que devem ser melhorados.

Concluindo, pode-se dizer que a implantaçăo do Programa de Avaliaçăo da Escola Pública de Minas Gerais, numa perspectiva integrada e participativa de toda a comunidade educacional, começa a se efetivar, o que pode ser evidenciado a partir dos ganhos que podem ser considerados após análise do contexto no Estado. Hoje, o surgimento de uma cultura de avaliação começa a ser observada e a incorporaçăo dos resultados na formação de políticas e no planejamento do ensino já é uma realidade.

Em decorrência dos resultados obtidos das experiências já realizadas, escolas, 6rgãos regionais e a propria Secretaria de Estado da Educação começam a planejar melhor e consolidar as metas básicas da educação.

Entre elas destacam-se:

- melhor uso do dinheiro público que vai ser aplicado na escola;

- treinamento de recursos humanos planejados conforme evidencias detectadas por regiäo;

- materiais pedag6gicos e equipamentos distribuídos conforme necessidade das escolas;

- mudanças necessárias nos currículos já acionadas para melhorar o aprendizado dos alunos;

- participaçăo dos pais nas escolas a cada dia mais efetiva.

Ainda há muito a ser feito, mas agora, após a realizaçăo do $1^{\circ}$ e $2^{\circ}$ ciclos do programa, escolas e governo já conhecem a sua realidade, já discutem o que precisa ser melhorado, e as açőes já são mais concretas em todo o Estado.

Todos já estão comprometidos com a qualidade da educaçăo.

\section{REFERÊNCIAS BIBLIOGRÁFICAS}

ABRAMOWICZ, M. Avaliação, tomada de decisões e políticas:subsídios para um repensar. Estudos em Avaliação Educacional, jul/dez, n 10. Fundação Carlos Chagas, São Paulo - 1994

BLOOM, B. et al. Manual de Avaliação Formativa e Somativa da Aprendizagem do Estudante. Ed. Pioneira. 1983.

HIMMEL, E. Medición de los resultados educativos: el caso de Chile Ouro Preto. Paper apresentado no Seminário Sobre Procedimento Edu- 
cacional. Secretaria de Estado da Educaçăo de Minas Gerais, em Ouro Preto, Minas Gerais, 1993.

POPHAM, W.J - Avaliação Educacional, Editora Globo, Rio de Janeiro, 1983. VIANNA, H. M. et al. - Desenvolvimento de um programa de avaliação do Sistema Estadual de Ensino: o exemplo de Minas Gerais. Estudos em Avaliaçăo Educacional, jul-dez, $\mathrm{n}^{\circ}$ 8. Fundaçäo Carlos Chagas. São Paulo, 1993. 